\title{
Census of the endangered Mexican long-nosed bat Leptonycteris nivalis in Texas, USA, using thermal imaging
}

\author{
Loren K. Ammerman ${ }^{1, *}$, Molly McDonough ${ }^{1,3}$, Nickolay I. Hristov ${ }^{2,4}$, \\ Thomas H. Kunz \\ ${ }^{1}$ Department of Biology, ASU Station Box 10890, Angelo State University, San Angelo, Texas 76909, USA \\ ${ }^{2}$ Center for Ecology and Conservation Biology, Department of Biology, 5 Cummington Street, Boston University, \\ Boston, Massachusetts 02215, USA \\ ${ }^{3}$ Present address: Department of Biological Science, Box 43131, Texas Tech University, Lubbock, Texas 79409, USA \\ ${ }^{4}$ Present address: Department of Ecology and Evolutionary Biology, 80 Waterman Street, Brown University, \\ Providence, Rhode Island 02912, USA
}

\begin{abstract}
Emory Cave in west Texas, USA is one of the few natural roost sites used by the endangered Mexican long-nosed bat Leptonycteris nivalis in the United States. Despite concern over declines in population size, no reliable methods have been developed for censusing colonies of this species that are both accurate and minimize disruption to the colony. The objective of this study was to use non-invasive thermal infrared imaging to census L. nivalis as individuals emerge from Emory Cave and to evaluate the success of this method for future monitoring efforts. We recorded 6 emergences of bats from Emory Cave (4 and 5 June, 4 and 5 July, 4 and 5 August 2005) using thermal infrared cameras. Recordings were manually reviewed, and peak emergence rate was determined to be 54, 159, and 61 bats $\mathrm{min}^{-1}$ in June, July and August, respectively. The greatest number of L. nivalis (at least 2742 to 2874) was present in July. Overall, our data suggest that thermal infrared imaging provides a more reliable and accurate estimate of the number of L. nivalis at Emory Cave than has previously been possible using extrapolation from surface area of the cave ceiling covered by bats.
\end{abstract}

KEY WORDS: Thermal infrared imaging - Census ' Leptonycteris nivalis - Emergence . Big Bend National Park · Emory Cave $\cdot$ Mexican long-nosed bat

\section{INTRODUCTION}

The Mexican long-nosed bat Leptonycteris nivalis is recognized as an endangered species by the State of Texas, the United States, and Mexico. This species occurs throughout much of Mexico, and reaches the northern limits of its distribution in the southwestern US (Hensley \& Wilkins 1988). It has been more than $50 \mathrm{yr}$ since the first (and only) known maternity roost in the US was described at Emory Cave, Big Bend National Park (BBNP) located in the Chisos Mountains of Texas (Borell \& Bryant 1942). L. nivalis inhabits this cave during the summer months, and likely spends the remaining months in Mexico. Numbers are known to fluctuate throughout the summer, presumably in response to the flowering phenology of Agave, as was observed by Moreno-Valdez et al. (2004) in Nuevo Leon, Mexico. Numbers of $L$. nivalis are reportedly declining (Wilson 1985), yet no reliable data on colony size and roost use exist to adequately address this concern.

Although the Chisos Mountains are the most visited region of BBNP, there has been no special effort to prevent park visitors from disturbing this vital roost. Other important threats to the survival of this species 
may include competition for roosts and nectar. Leptonycteris nivalis is known to feed on nectar and pollen of at least 21 plant species, representing 10 families, including species primarily in the families Amaryllidaceae, Bombacaceae, Bignoniaceae, Cactaceae, Convolvulaceae, and Fabaceae (Hensley \& Wilkins 1988, Sanchez \& Medellín 2007), and thus it is thought to play an important role in pollination of these plants and in the maintenance of arid-land ecosystems. In the Chisos Basin of BBNP, Kuban (1989) found that $L$. nivalis is the most effective pollinator of Agave havardiana. The impact of Agave and cactus removal for agriculture, ranching, and human development on the colony has not been determined.

Both state and federal recovery plans recognize the need for accurate, long-term monitoring of Leptonycteris nivalis to understand, and ultimately protect this species. Traditional mist-netting techniques for determining the presence of this species have proven unsuccessful. In fact, in the past $12 \mathrm{yr}$ of netting over water sources in BBNP, only 3 ind. out of over 4600 captures have been of this species (Higginbotham \& Ammerman 2002, L. K. Ammerman unpubl. data). To effectively monitor numbers of $L$. nivalis using mist net captures, efforts must be concentrated around Agave plants - and this method poses important logistical challenges, especially in BBNP.

Roost counts have been conducted at Emory Cave in most years since 1988 and suggest major inter-year fluctuations in colony size (R. Skiles pers. comm.). Estimates range from none (in 1994 and 2002) to 6630 bats (in 1988). However, these estimates have been conducted only once each year by counting the number of roosting bats $\mathrm{m}^{-2}$ and then extrapolating this to the estimated area of the roost that is covered by bats (Thomas \& LaVal 1988). This method is potentially biased and disruptive to the colony (Kunz 2003), and recently it has been discovered (England 2004) that some bats either roost in inaccessible crevices or are widely dispersed in the cave and thus cannot be observed and counted. Visual estimates of colony size, by counting bats as they emerge at dusk, are also difficult because of low light, dense vegetation, and the large numbers of individuals that circle at the cave opening prior to and during nightly emergence. An added complication for all methods previously used to census Leptonycteris nivalis at Emory Cave is that 2 other species, Myotis thysanodes and Corynorhinus townsendii, also use this cave in low numbers.

Recent developments in thermal infrared imaging and computer vision techniques make it possible to census bats as they emerge nightly from caves and other roosting places, obviating the need to enter roosts to census bats - a method that is known to cause disturbance (Kunz 2003). Because thermal infrared cameras detect heat produced by bats, it is possible to record and census bats independently of ambient light (Kunz 2003, Hristov et al. 2008). This method has proven successful for censusing Brazilian free-tailed bats Tadarida brasiliensis, where millions of bats emerge nightly from selected caves in Texas (Frank et al. 2003, Betke et al. 2008). The use of infrared thermal imaging to census bats that roost in Emory Cave is an important improvement over the surface area method because it is less disruptive to the bat colony and records all bats during the nightly emergence at dusk, thus accounting for bats that otherwise would be overlooked when roosting in inaccessible crevices or sections of the cave.

The objective of this study was to use non-invasive thermal infrared imaging to census Leptonycteris nivalis as individuals emerge from Emory Cave, BBNP. The morning following a nightly emergence, surface area estimates were made for comparison to the estimates from thermal recordings. Our objectives directly addressed 2 of the goals of the North American Bat Conservation Plan for establishing baseline estimates of colonies: (1) to develop and evaluate new monitoring methods and (2) establish and monitor colony size.

\section{MATERIALS AND METHODS}

We conducted a preliminary study on 19 July 2004 to evaluate possible camera placement to optimize future census efforts. In 2005, we conducted 6 censuses of bats that emerged from Emory Cave (4 and 5 June, 4 and 5 July, 4 and 5 August). We recorded the entire emergence of bats from the main opening of the cave for approximately 1 to $1.5 \mathrm{~h}$ each night using a FLIR S65 thermal infrared camera $(320 \times 256$ pixel uncooled microbolometer focal plane array, recording at 60 frames per second) (FLIR Systems). Data were recorded and saved onto the hard drive of a laptop computer. The tripod-mounted camera was positioned in the upper right section inside the cave opening on a rock shelf, perpendicular to the flight direction of emerging bats. The bats flew from right to left and out of the cave over and through the foliage of a hophornbeam tree Ostrya chisosensis, that partially blocked the main entrance to the cave.

Recordings of each emergence were played back on a laptop computer using ThermaCAM Researcher Pro 2.8 software (FLIR Systems) and bats were manually counted (Fig. 1). The numbers of bats emerging from and entering the cave were scored each second. These data were used to determine an emergence rate (number of bats leaving $\mathrm{min}^{-1}$ ) and a net number of bats each minute (subtracting number emerged from the number that entered). Because 3 species of bats roost 


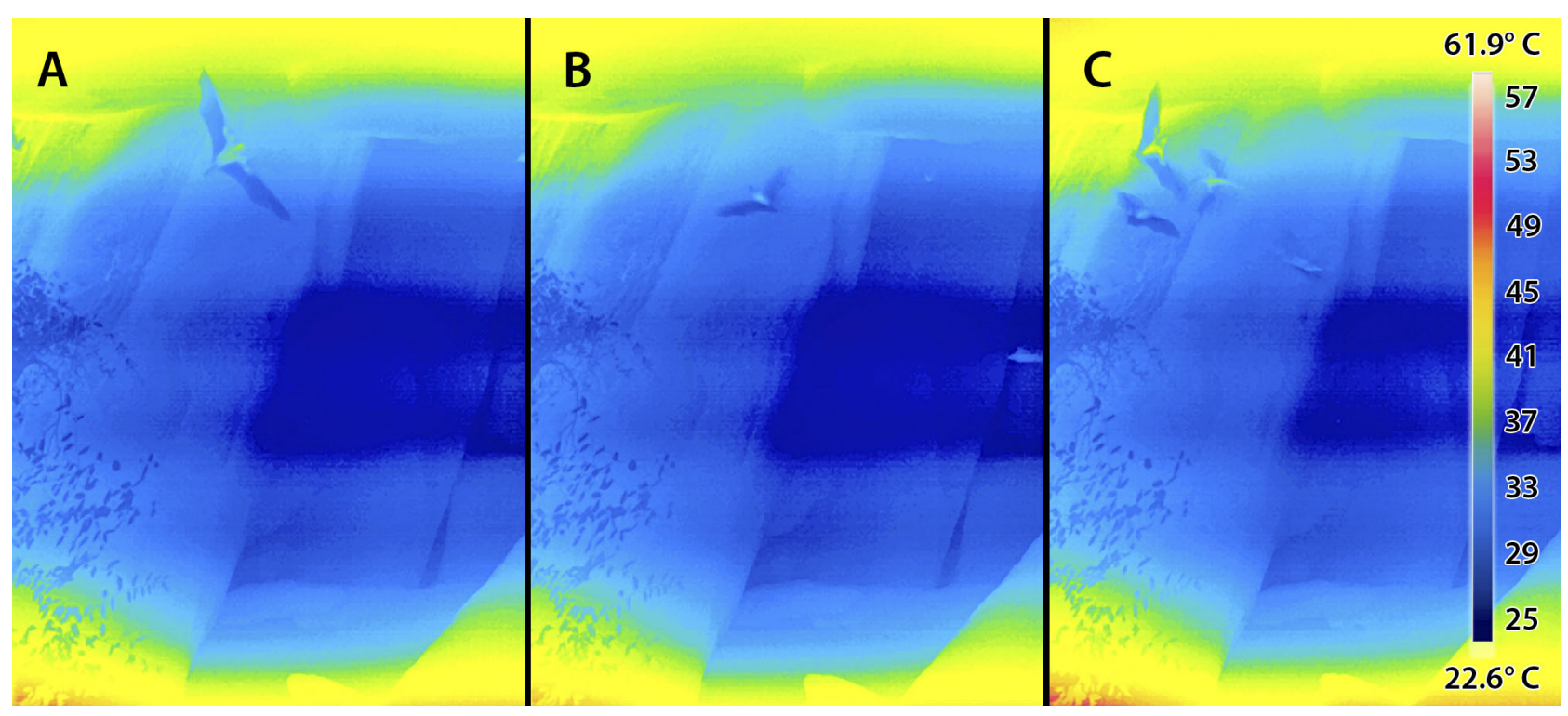

Fig. 1. Leptonycteris nivalis and Corynorhinus townsendii. Thermal infrared images (false color) of bats emerging from Emory Cave, Big Bend National Park. Cool wings and ears of the bats appear blue-black, whereas the warm torsos appear yellow-green. A hophornbeam tree Ostrya chisosensis is in the foreground. (A) L. nivalis. Note the prominent forearm musculature forming a ' $\mathrm{T}$ ' shape with the torso in yellow. (B) C. townsendii lacks the ' $\mathrm{T}$ ' shape, and cool ears and uropatagium are visible. (C) A comparison of $L$. nivalis and C. townsendii emerging from Emory Cave

in Emory Cave (Myotis thysanodes, Corynorhinus townsendii, and Leptonycteris nivalis), and because we could not always confidently distinguish among these species with the thermal infrared camera, our emergence counts include all 3 species. However, based on body shape and wing structure (Fig. 1), we were often able to distinguish $L$. nivalis from the vespertilionids.

A second S-65 thermal infrared camera was used to monitor a small 'skylight' located above the main opening in June and July to determine whether bats also used this opening. No bats exited or entered through this opening during the emergence periods. This opening is not well characterized and is difficult to access because it is high on a west-facing bluff above the main cave opening. Following the emergence of bats, the precise location of the opening was confirmed by shining a bright spotlight through the opening from within the cave and positioning observers outside of the cave to verify the location of the glow from the light. From this observation it was determined that the opening is partially obstructed by vegetation or rocks because the light we observed was diffuse.

Estimates of surface area inside the cave were conducted by 2 observers on 6 July and 6 August 2005 immediately after the bats had returned at sunrise. Surface area estimates were calculated using 2 different density estimates from the literature as follows: 150 bats $\mathrm{ft}^{-2}\left(1613\right.$ bats m$\left.^{-2}\right)$ (Easterla 1972) and 62 bats ft $^{-2}(667$ bats $\mathrm{m}^{-2}$ ) (D. J. Howell unpubl. data).
Temperature and relative humidity data loggers (HOBO, Onset Computer Company) were placed in the cave on 4 July and removed on 5 August 2005. One logger was placed in the main room where bats often roosted and one was used to monitor conditions in the outermost chamber, near the cave entrance. Temperature and relative humidity were recorded once every hour.

\section{RESULTS}

Recordings from 6 nights were analyzed. The number of bats exiting, entering, and estimates of surface area covered by roosting bats is summarized in Table 1 . The peak emergence rate in June was 54 bats $\mathrm{min}^{-1}$ at 21:42 h Central Daylight Time (CDT) (48 min after sunset), the peak emergence rate in July was 159 bats $\mathrm{min}^{-1}$ at 21:56 h CDT (56 min after sunset), and the peak in August was 61 bats $\min ^{-1}$ at $21: 23 \mathrm{~h}$ CDT (38 min after sunset) (see averages in Fig. 2). These values do not reflect the number of bats reentering the cave. A measure of net emergence (number of bats exiting minus number entering) was calculated each minute. The total number of bats emerging was highest in July (Table 1).

On 6 July, bats were estimated to cover $1.4 \mathrm{~m}^{2}$ of ceiling area (Table 1). In August, from within the cave, hundreds of bats were heard returning shortly before sunrise; however, when the noise level decreased and 
Table 1. Leptonycteris nivalis, Corynprhinus townsendii and Myotis thysanodes. Results of census analysis at Emory Cave on 6 different nights during the summer of 2005. Net emergence was calculated by subtracting the number of bats entering from the number that exited. Surface area estimates were calculated using D. J. Howell's (unpubl. data) and Easterla's (1972) density estimates.

$(-)$ No surface area estimates

\begin{tabular}{|lcccc|}
\hline Date & $\begin{array}{c}\text { Number of } \\
\text { bats exiting }\end{array}$ & $\begin{array}{c}\text { Number of } \\
\text { bats entering }\end{array}$ & $\begin{array}{c}\text { Net } \\
\text { emergence }\end{array}$ & $\begin{array}{c}\text { Surface area estimate } \\
\text { (number of bats) }\end{array}$ \\
\hline 4 June & 892 & 520 & 372 & - \\
5 June & 617 & 183 & 434 & - \\
4 July & 4812 & 1295 & 3517 & - \\
5 July & 4311 & 926 & 3385 & - \\
4 August & 958 & 105 & 853 & 0 \\
5 August & 759 & 117 & 642 & \\
\hline
\end{tabular}

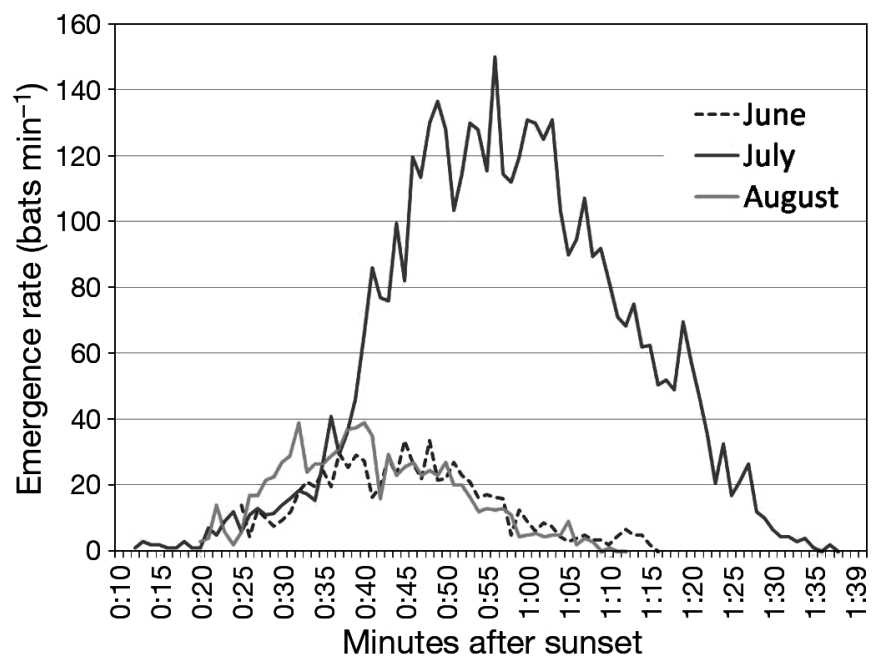

Fig. 2. Average emergence rate (bats $\mathrm{min}^{-1}$ ) from Emory Cave calculated from 2 nights each in June, July, and August of 2005. These values include all 3 species known to roost in the cave (Leptonycteris nivalis, Corynorhinus townsendii, and Myotis thysanodes)

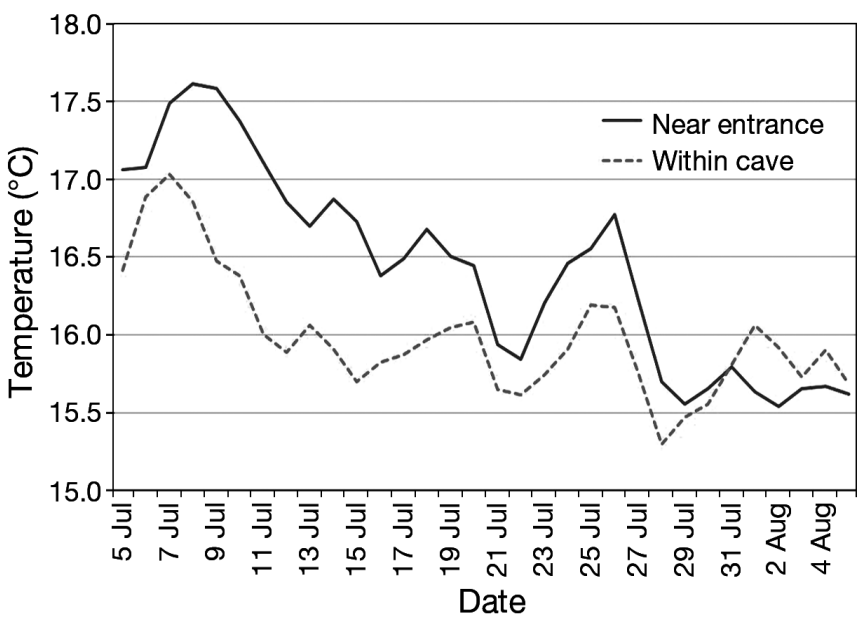

Fig. 3. Average daily temperature fluctuations recorded at 2 locations within Emory Cave during summer 2005 our headlamps were turned on there were no bats observed in the main room of the cave. Because we could hear chattering noises from bats coming from below where we stood, it seemed obvious that they occupied deep passageways of the cave that were inaccessible to us. Thus, in August, although we had filmed bats emerging from the cave the previous night, we were unable to obtain an estimate of surface area covered by roosting bats, resulting in an obvious discrepancy in the number of bats counted using the 2 methods in August. Moreover, no estimates of roosting bats could be made in June because there was no sign of fresh guano this early in the summer to aid in the location of the occupied roost. We observed approximately 60 flightless juvenile Corynorhinus in the main room of the cave following the emergence of adults on 4 June. Many discarded moth wings and large amounts of insectivorous bat guano were observed scattered on the cave floor. Assuming that this cluster of young bats was the only such aggregation of Corynorhinus in June, and together with the fact that this species typically produces singleton pups (Pearson et al. 1952), we would expect at least 60 adult females of this species to occupy Emory Cave in early June.

The average temperature in the cave from 4 July to 5 August was $16.4^{\circ} \mathrm{C}$ in the main room (range 15.2 to $18.3^{\circ} \mathrm{C}$ ) and $16^{\circ}$ in the outer chamber (range 14.9 to $19.4^{\circ} \mathrm{C}$ ). Fluctuations were greater near the entrance than in the main room (Fig. 3). Before 18 July, relative humidity averaged $78 \%$ in the outer room and $87.7 \%$ in the main room. These recordings were unreliable after 18 July 2005 in the main room because, we suspect, the sensor of the data logger malfunctioned due to excessive moisture.

\section{DISCUSSION}

\section{Size of Leptonycteris colony}

The peak size of the Leptonycteris colony was observed in July as was previously documented (Easterla 1972, D. J. Howell unpubl. data). The precise number of Leptonycteris can be estimated from information about the number of Corynorhinus and Myotis that were observed in the cave in June and August. We discovered that we could distinguish between Leptonycteris and the 2 vespertilionid species that also emerge from the cave using the thermal images, 
but we were not able to reliably distinguish Corynorhinus from Myotis when in flight. Specifically, the forelimb musculature of Leptonycteris is very pronounced and produces a diamond-shaped or $\mathrm{T}$ shaped thermal image, whereas the Myotis and Corynorhinus images are torpedo-shaped (Fig. 1). Based on this difference, we are confident that Leptonycteris was present in all 6 emergences that we analyzed. In July, we estimated that approximately 10 to $15 \%$ of all the bats counted were Leptonycteris. In August, we counted Leptonycteris and the 2 vespertilionid species separately. A conservative estimate of Leptonycteris present in August was at least 210 out of the 853 bats that emerged at dusk. The remaining bats were vespertilionids (643 on 4 August). If we assume that the number of vespertilionids emerging from the cave in August was similar to the number present in July, then it would mean that in July when Leptonycteris was at its peak colony size, at least 2742 to 2874 L. nivalis were present. The number of vespertilionids that we recorded emerging from the cave in June (estimated as 326 to 380) was about half the number counted in August (643), which is consistent with our expectation because the pups were not volant in June. Thus, the estimated colony size of Leptonycteris nivalis at Emory Cave in July was similar in magnitude to numbers reported by Moreno-Valdez et al. (2004) for El Infierno Cave in Nuevo Leon, Mexico.

\section{Comparison of surface area estimate and emergence counts}

Estimates of surface area covered by roosting bats are generally fraught with error (Kunz 2003). Density estimates of Leptonycteris nivalis range from 62 bats $\mathrm{ft}^{-2}\left(667\right.$ bats $\left.\mathrm{m}^{-2}\right)$ to 150 bats $\mathrm{ft}^{-2}$ (1613 bats $\mathrm{m}^{-2}$ ) (Easterla 1972, D. J. Howell unpubl. data). Our estimates of surface area covered by the bats also varied widely. As an experiment, one of us (L. K. Ammerman) showed a group of 35 undergraduate biology students a photograph of the cave ceiling taken on 6 July and asked each to estimate the number of bats present using 62 bats $\mathrm{ft}^{-2}$ (667 bats $\mathrm{m}^{-2}$ ) as a density estimate; their estimates ranged from 434 to 6912 (mean of 2031).

The wide discrepancy between the emergence count and surface area estimate in August is an additional cause for concern regarding the validity of previous estimates of colony size using the roost estimate method. It is not certain that previous estimates of colony size actually reflect an absence of bats. It is quite possible, as we observed, that bats were roosting in parts of the cave that were inaccessible to human observers on dates when the censuses were conducted. If additional information, such as lack of fresh guano on the date of a census were available, it could substantiate the zero estimate in those years.

During our study, we observed bats returning to the cave at dawn and passing through the main room into passageways inaccessible to us. We suggest that these bats were possibly avoiding an unidentified potential predator that we heard moving around on a high shelf in the main room or were seeking parts of the cave that were more energetically suitable. Unfortunately, the predator was never observed; however, raccoons Procyon lotor and striped skunks Mephitis mephitis are known mammalian predators on bats in Texas caves (Davis et al. 1962). Essentially nothing is known about the precise roosting habits of Leptonycteris nivalis at this time of year. Regardless of the reason for the bats' use of the main room on some days, this situation creates a problem with respect to the interpretation of data reported from previous years that are needed to establish trends in colony size. Further study of the use of the main room versus deeper chambers will be important to identify variables that may be correlated with deep chamber occupancy by bats (such as temperature, relative humidity, barometric pressure, predator avoidance).

\section{Thermal infrared imaging}

Thermal infrared imaging has several advantages over other methods that have been used to census bats (Betke et al. 2008, Hristov et al. 2008). It provides a high resolution, permanent record of the emergence, and it results in less human error. It is also less disturbing to bats than entering the cave to count roosting bats or using supplemental light sources during emergence to film, photograph, or videotape emerging bats. Moreover, an added advantage for this study was the definition of bat images, when recorded at relatively short distances, making it possible to at least distinguish Leptonycteris nivalis from co-inhabiting vespertilionid bats based on differences in body shape and relative size of forearm musculature. Disadvantages include the relatively high cost of a thermal infrared camera (ca. \$60000 USD), occasional failure of the camera and computer in the field, and time required for manual data analysis. An additional disadvantage is that currently the results cannot be directly compared to previous census data. Despite these shortcomings, our data suggest that thermal infrared imaging can provide a more reliable and accurate estimate of the number of bats occupying Emory Cave during the summer months than has previously been possible. Current efforts are underway to develop algorithms to automatically detect, track, and count emerging bats (Betke et al. 2007, Hristov et al. 2008) using data derived from an uncooled FLIR S-65 thermal infrared camera. 


\section{CONCLUSIONS}

Average cave temperature was slightly warmer than documented for El Infierno Cave in Nuevo Leon, Mexico $\left(12.1^{\circ} \mathrm{C}\right.$ in August) (Moreno-Valdez et al. 2004), but is still cooler than many known maternity roosts used by other species of cave-roosting bats (Kunz 1982). Consistent with previous workers (Easterla 1972), we did not observe non-volant Leptonycteris pups in Emory Cave; thus we expect that parturition occurred before bats migrated to Emory with their volant young. Based on previous cave surveys, the Emory Cave colony of $L$. nivalis presumably experiences large annual fluctuations consistent with expectations of a 'spillover' colony as described by Easterla (1972); however, the location of maternity roosts, seasonal patterns of roost occupancy, and migratory movements are still largely unknown for this species (Hensley \& Wilkins 1988, England 2004, Moreno-Valdez et al. 2004). Future studies that incorporate surveys of flowering phenology of food plants, reliable cave censuses, assessments of sex and age structure, as well as the genetic composition, of these 2 important sites are necessary to provide a greater understanding of the migratory habits and the role of Emory Cave in the life history of this species.

Acknowledgements. We thank Louise Allen, Carson Brown, Michael Dixon, Travis Fisher, Rogelio Rodriguez, Raymond Skiles and Anna Strong for valuable assistance. This research was conducted under a scientific research permit (BIBE-2005SCI-0037) from the US National Park Service, and supported by grants from Bat Conservation International to L.K.A. and T.H.K., and the National Science Foundation (EIA-ITR 0326483) to T.H.K., M. Betke, G. F. McCracken, J. K. Westbrook and P. W. Morton.

\section{LITERATURE CITED}

Betke M, Hirsh DE, Bagchi A, Hristov NI, Makris NC, Kunz TH (2007) Tracking large variable numbers of objects in clutter. Proceedings of the IEEE Computer Society June 2007. Conference on Computer Vision and Pattern Recognition, Minneapolis, MN

Betke M, Hirsh DE, Makris NC, McCracken GF and others (2008) Thermal imaging reveals significantly smaller Brazilian free-tailed bat colonies than previously esti-

Editorial responsibility: Stephen Rossiter,

London, UK mated. J Mammal 89:18-24

Borell AE, Bryant MD (1942) Mammals of the Big Bend area of Texas. Univ Calif Publ Zool 48:1-62

Davis RB, Herreid CF II, Short HL (1962) Mexican free-tailed bats in Texas. Ecol Monogr 32:311-346

Easterla DA (1972) Status of Leptonycteris nivalis (Phyllostomidae) in Big Bend National Park, Texas. Southwest Nat $17: 287-292$

England AE (2004) Radio-tracking of the greater long-nosed bat, Leptonycteris nivalis, in Big Bend National Park, Texas. Bat Res News 40:95-96

Frank JD, Kunz TH, Horn J, Cleveland C, Petronio S (2003) Advanced infrared detection and image processing for automated bat censusing. Infrared Technology and Applications XXIX. Proc SPIE 5074:261-271

$>$ Hensley AP, Wilkins KT (1988) Leptonycteris nivalis. Mamm Species 307:1-4

Higginbotham JL, Ammerman LK (2002) Chiropteran community structure and seasonal dynamics in Big Bend National Park. Spec Publ Mus Tex Tech Univ 44:1-44

> Hristov NI, Betke M, Kunz TH (2008) Applications of thermal infrared imaging for research in aeroecology. Integr Comp Biol 48:50-59

Kuban JF (1989) The pollination biology of two populations of the Big Bend century plant, Agave havardiana: a multiple pollinator syndrome with floral specialization for large vertebrate pollinators. PhD dissertation, Syracuse University, New York

Kunz TH (1982) Roosting ecology of bats. In: Kunz TH (ed) Ecology of bats. Plenum Press, New York, p 1-55

Kunz TH (2003) Censusing bats: challenges, solutions, and sampling biases. In: O'Shea TJ, Bogan MA (eds) Monitoring trends in bat populations of the United States and Territories: problems and prospects. US Geological Survey, Sciences Division, Biological Resources Discipline, Information and Technology Report USGS/BRD/ ITR-2003-003. Washington, DC, p 9-20

Moreno-Valdez A, Honeycutt RL, Grant WE (2004) Colony dynamics of Leptonycteris nivalis (Mexican long-nosed bat) related to flowering Agave in northern Mexico. J Mammal 85:453-459

Pearson OP, Koford MR, Pearson AK (1952) Reproduction of the lump-nosed bat (Corynorhinus townsendii) in California. J Mammal 33:273-320

- Sanchez R, Medellín RA (2007) Food habits of the threatened bat Leptonycteris nivalis (Chiroptera: Phyllostomidae) in a mating roost in Mexico. J Nat Hist 41: 1753-1764

Thomas DW, LaVal RK (1988) Survey and census methods. In: Kunz TH (ed) Ecological and behavioral methods for the study of bats. Smithsonian Institution Press, Washington, DC, p 77-89

Wilson DE (1985) Status report: Leptonycteris nivalis (Saussure) Mexican long-nosed bat. Office of Endangered Species, US Fish and Wildlife Service, Washington, DC

Submitted: June 1, 2008; Accepted: November 3, 2008

Proofs received from author(s): February 16, 2009 